\title{
Timothy O'Connor, Persons \& Causes: The Metaphysics of Free Will. Oxford \& New York: Oxford University Press, 2000. Pp. Xv and 135. $\$ 35.00$
}

\section{Andrei A. Buckareff \\ University of Rochester}

In the past decade, Timothy O'Connor has established himself as one of the leading defenders of the agent-causal theory of free action. In Persons \& Causes, O'Connor provides a sophisticated defense of incompatibilist freedom and his own agent-causal and volitional theory of the etiology of action. He includes an account of a non-causal theory of the role of reasons in the explanation of action and a defense of emergentism as a means of making sense of how agents can possess the requisite active powers for them to act freely. Additionally, O'Connor critiques the most prominent alternatives to the agency theory at providing a libertarian theory of free action, as well as other varieties of the agency theory. Altogether, he provides a solid assessment and critique of the major alternatives to the agency theory, coupled with what is perhaps the best recent defense of a traditional agent-causal theory of free action.

O'Connor begins chapter one of his book by considering the implications of determinism for human freedom by evaluating some modal principles that have undergirded recent arguments for incompatibilism. The modal notions in question are encapsulated in what Peter van Inwagen dubbed the consequence argument. The argument involves an analysis of the transfer of power necessity that results from past events and the laws of nature if determinism is true. The transfer of necessity that obtains is such that if at some time $t_{2}$ agent $S$ wills to $V$, and if $S$ 's willing to $V$ is causally necessitated by the laws of nature and some earlier event at $t_{l}$ beyond $S$ 's control at $t_{l}$, then $S$ 's choice and subsequent action $V$ were not up to $S$. Therefore, $S$ 's action was not free. 
The remainder of the chapter is devoted to arguing for the cogency of the argument for incompatibilism, as well as a brief consideration of the kinds of responses offered by compatibilists to such arguments. Finally, he concludes by offering a brief analysis of the problem of moral responsibility (taken up again in chapter four). He considers Frankfurt-style counterexamples to the Principle of Alternate Possibilities (PAP)—defending the "flicker of freedom" defense of some form of PAP and critiquing John Martin Fischer's semi-compatibilism (the view that free will and determinism are incompatible, but moral responsibility and determinism are compatible).

Having argued for the incompatibility of freedom with determinism, O'Connor puts forth two basic conditions for responsible agency in chapter two. The first requirement is that one must provide a clear account of agent control. Libertarians have often been criticized for defending a theory of erratic agency; thus, their burden has traditionally been to provide an adequate account of rational agency and agent control, an onus compatibilists have traditionally not had to shoulder. Second, "an account of human free agency ... must allow for there being alternative courses of action that are genuinely open to the agent" (p. 24). For the libertarian this has not been a problem; however, the compatibilist has faced difficulties trying to provide an adequate account of what it means for someone to have genuine alternatives.

O'Connor first examines the efforts of simple indeterminists (specifically, Carl Ginet) and causal indeterminists (Storrs McCall, Robert Nozick, and Robert Kane) at providing a compelling theory of libertarian free agency. He concludes that both the simple indeterminist and causal indeterminist fail to provide satisfactory accounts of agent control. The simple indeterminist's analysis of agent control, "implicitly requires that the core mental events are entirely uncaused" (p. 27). O'Connor adds that, "if fundamental physical processes are causally connected (perhaps indeterministically), supposing there are free decisions in accordance with this analysis is inconsistent with a materialist and even an emergent dualist account of human mental activity" (p. 27). On the other hand, probabilistic causal analyses of agent control, despite some distinctions between the theories, suffer from 
similar problems over explaining agent control, according to O'Connor. "[T] he causal indeterminist needs to confront directly the challenge of explaining how it is that an agent can have a choice about which potential indeterministic cause will be efficacious in a given situation" (pp. 29-30). O'Connor argues none of the extant theories offered to date have effectively accomplished this task.

In chapters three and four, O'Connor considers the agency theory as a means of providing a more effective defense of a libertarian theory of free action. In chapter three he focuses on the defenses of the agency theory proffered by Thomas Reid, Roderick Chisholm, and Richard Taylor. O'Connor's treatment of Chisholm, in particular, is outstanding and reflects a deep familiarity with Chisholm's work. Great care is taken in an appendix to chapter three trying to understand the development of Chisholm's thought from the agency theory into a disingenuous variety of simple indeterminism and, finally, to an outright rejection of the agency theory in favor of regarding agent-causation as a subspecies of event-causation.

O'Connor notes that Richard Taylor is one of a few action theorists who has provided an account of the agency theory not as a means of defending a libertarian theory of free action, but to understand action simpliciter. Taylor suggested the concept of agency is compatible with determinism and does not require any particular commitments to an account of free action.

O'Connor argues that Taylor's account suffers from two major problems. First, O'Connor contends that one's being the agentcause of all of one's actions "undercuts the utility of the agency theory as a solution to the metaphysical problem of human responsibility and freedom" (p. 51). Some of our actions are not free, and O'Connor maintains that those actions are not agentcaused. But the problem with O'Connor's criticism is that he fails to see how much more consistent Taylor was in his days of defending the agency theory (he has since rejected agent-causation) than those like O'Connor who defend the agency theory while maintaining that at least some actions are not agent-caused and are determined by event-causes. O'Connor never provides a satisfactory account of what mechanism would be responsible for when an action is caused by an agent and when an action is not 
agent-caused. In chapter six, under the heading of his discussion of emergent active powers, $O^{\prime}$ Connor even admits that, "[an] issue an emergentist version of the agency theory faces is a result of the fact that if there are agent-causal events, there is no neat and simple way of dividing them from event-causal ones"' (p. 122). O'Connor fails to provide a satisfactory account of how event- and agentcausal processes interact (see p. 123). Taylor at least takes all actions to be agent-caused. His theory is simpler and perhaps preferable on that level. But Taylor's theory suffers from deficiencies, evinced by O'Connor's second criticism.

O'Connor's second criticism generates genuine problems for Taylor. For Taylor, agent-causation is conceptually primitive, but its ontological status is questionable. As a result confusion arises in his theory when explaining how agent-caused actions can be caused, and thus determined, by an event. More specifically, O'Connor asks, "Just how are we to understand the notion of an exercise of active power itself produced by some prior factor?" (p. 52). If the agent-causing of an action is ontologically primitive, then it would seem it would make no sense to describe an agent causing her action as following from an event that is sufficient for her to cause her action. As O'Connor notes, "If A's doing $e$ always consists of A's causing $e$, then A's doing $e$ does entail that A is not caused to do $e$ " (p. 55). (One would want to add that "A's causing $e$ " would have to be irreducible to an event-causal relation of the sort posited by the causal indeterminist. For the causal indeterminist may be willing to agree that agent-causation is conceptually primitive where the agent-causal relation is simply reducible to an event-causal relation.)

In chapter four O'Connor develops his own views, contrasting them with the hybrid causal agent-causal theory of action (an agentcausal theory of action that incorporates a causal indeterminist theory of acting for reasons) defended by Randolph Clarke. Additionally, he addresses the standard challenge to the coherence of the agency theory, specifically the intelligibility of causation by a substance, as offered by C.D. Broad and built upon by others since. He also critiques Raziel Abelson's ersatz agent-causalism and reexamines PAP and how the agency theory can be used to defuse Frankfurt-style cases. 
O'Connor takes agent-causation to embody "the same primitive feature of causal production, or oomph, at work in event causation, the differences consisting in the way that certain properties contribute to the causal potentialities of objects that have 'active power"' (p. 67). More specifically, he defends a realist theory of event-causation where objects manifest causal powers that are observable in their effects. The relevant causal powers are based in an object's underlying nature. The powers are features of clusters of properties linked with functions to effects from circumstances (p. 71). O'Connor writes, following R. Harre and E.H. Madden, that, "Circumstances prompt the exercise of a power in one of two ways: either by stimulating a latent mechanism to action or by removing inhibitors to the activity of a mechanism in a state of readiness to act" (p. 71). O'Connor uses the example of turning a car's ignition key as an example of a mechanism-triggering event; and the displacement of air from an underwater cylinder, "which enables the body of water to crush the object," as an example of a barrier-removing event (p. 71).

In the case of agent-causation, the agent causes a state of intention that gives rise to further actions. He proffers the following account.

$[\mathrm{P}]$ arallel to event causes, the distinctive capacities of agent causes ('active powers') are grounded in a property or set of properties. So any agent having the relevant internal properties will have it directly within his power to cause any of a range of states of intention delimited by internal and external circumstances. However, these properties function differently in the associated causal process. Instead of being associated with 'functions from circumstances to effects,' they (in conjunction with appropriate circumstances) make possible the agent's producing an effect. These choiceenabling properties ground a different type of causal power of capacity - one that in suitable circumstances is freely exercised by the agent himself. (p. 72)

O'Connor anticipates objections to such an account, in particular his simultaneously holding to a causal powers theory of 
event causation, which is an antisingularist variety of causal realism, while defending an account of agent-causation that implies singularism. Singularists hold that causation is not general, in the sense that the presence of certain event-types does not entail that they will always cause a certain type of event. Unfortunately, $O$ 'Connor seems to wave off any problems this discrepancy illumines in his account, suggesting that the problem is not with his account but with the current conception of the singularist/ antisingularist distinction (pp. 72-73).

Is such an account of agent-causation satisfactory? That is, has O'Connor genuinely illuminated and rendered intelligible the nature of the causal relationship the agency theorist claims obtains between an agent and her acting? For O'Connor, the event that is a basic action is initiated by the agent qua cause. To suggest otherwise would be to say that the causing of the basic action by the agent is an event discrete from the basic action. If such an event is introduced as the cause of the action, the agent and the event that follows the agent's causal activity would instance an event-causal relation-i.e., the agent-causal relation would then be reducible to an event-causal relation. But O'Connor insists that no such antecedent relation precedes the action, thus we are stuck with trying to understand a causal relation that resists any systematic explanation in intelligible terms. If we say that the agent brings about or causes the action, then, if we explicate what is meant by "the agent caused an event" in terms devoid of reference to causation by an event, we are left with a conceptually arcane account of what the relevant relation amounts to. O'Connor nowhere seems to adequately address this problem. The upshot is that he leaves the causal relation as sui generis, being inexplicable and unintelligible. In this respect, he does not advance beyond previous attempts at making sense of the agent-causal relation; his work on providing an account of event-causation as a model for agent-causal relations notwithstanding.

In chapter five, $O^{\prime}$ Connor argues for a non-causal theory of acting for reasons. Additionally, O'Connor considers the range of actions an agent undertakes that we can say are free. His account of reasons-explanations relies heavily on the work of Carl Ginet. The role of reasons in explaining actions is best regarded as 
teleological on O'Connor's account. Acting to satisfy an antecedent desire $D$ is to act in a manner an agent believed would be conducive to fulfilling her desire, the action being initiated by the selfdetermining causal activity of the agent. The conative state of desiring that $D$ is concurrent with the action, but plays no causal role, the action being the intended means of satisfying $D$. The intention is itself a causal consequence of the agent's causal activity. Moreover the intention is then the action-triggering event that "causally sustained the completion of the action" (p. 86). Note, however, that the explanation of the action in terms of a reason does not have recourse to the reason qua mental state that causes the action. Rather, it is the content of the state that seems relevant in O'Connor's account (a fact he does not make explicit). The reasons direct action, but they do not cause the action. Similar accounts of acting for reasons are defended by simple indeterminists like Hugh McCann and, as mentioned, Carl Ginet.

While such an account of reasons-explanations may be a promising route to go for the agency theorist, it seems the agency theorist, such as O'Connor, must explain why the reason-state does not have a causal function in the production of action. This problem seems especially acute for $\mathrm{O}^{\prime}$ Connor given that, as mentioned above, he believes there are instances when an agent's actions are not caused by the agent herself, but are the consequence of eventcausal processes. Suffice it to say that the problems he faces with the theory of the role of reasons in explaining actions are outweighed only by the aforementioned problems with intelligibly explaining the nature of the putative causal relation that obtains between an agent and her actions.

Finally, in chapter six, O'Connor develops an emergentist account of the active powers he suggests are involved in the causation of actions by agents. He writes that, "In calling some phenomenon 'emergent,' we intend to express the idea that it introduces a qualitatively new, macro-level feature into the world" (p. 111). The emergent properties relevant for O'Connor's theory of action would be agent-causal properties. Such a property is, "a nonstructural, natural property that is exemplified by objects or systems that attain the appropriate level and kind of organizational complexity and that exerts downward causation" (p. 111). In this 
case, the relevant object or system would be the agent who can exercise causation as a result of the supervenient property on the subvening base properties. Needless to say, such a move by $O$ 'Connor is creative and compelling and may lend more plausibility to the agent-causal theory of action. But this requires making a strong enough case for emergentism, a task O'Connor takes up, providing a preliminary emergentist account of consciousness and of the active power he claims would be the relevant causal property that would make causation by a substance intelligible. Notice, however, that O'Connor's task is a daunting one. Not only must he provide an adequate defense of emergentism-a task I believe he has taken significant steps to fulfill, but he must still convince his detractor that his theory of causation is viable. Furthermore, he must show that agent- and event-causation are not so different as to render his theory of causation irrelevant for the task of making sense out of the idea of nonoccurrent causation. While O'Connor has taken steps towards fulfilling these tasks in Persons and Causes, more work needs to be done.

Any criticisms aside, O'Connor's work is by far the best booklength defense of the agency theory to be published to date. He addresses the objections to the agency theory without compromising the central features of such a theory of action. Furthermore, he provides incisive analysis of the competing incompatibilist theories of free action, as well as providing a strong argument for incompatibilism more broadly. He examines the logical and metaphysical dimensions of the free will debate with clarity, depth, and a healthy dose of humility. In light of these features and others, O'Connor's book should be welcomed and read by those doing work in the philosophy of action, and it should prove to be of interest to those doing work in related areas in the philosophy of mind, metaphysics, and moral philosophy. 